\title{
SCIENTIFIC REPORTS

\section{Effects of methyl jasmonate on the growth and triterpenoid production of diploid and tetraploid Centella asiatica (L.) Urb. hairy root cultures}

\author{
Khoa Van Nguyen $\mathbb{1}^{1,2}$, Benyakan Pongkitwitoon $\mathbb{1}^{1}$, Thanika Pathomwichaiwat ${ }^{1}$, \\ Unchera Viboonjun $^{2}$ \& Sompop Prathanturarug ${ }^{1 *}$
}

In this study, the effects of methyl jasmonate (MeJA) on the phytomass and triterpenoid production of diploid and tetraploid Centella asiatica hairy roots were investigated. Hairy root cultures were obtained from diploid and induced tetraploid plants of $C$. asiatica infected by Agrobacterium rhizogenes strain ATCC 43057. MeJA triggered triterpenoid production in both ploidy hairy roots, whereas triterpenoids were not produced in the untreated hairy roots. Among the treatments, the $50 \mu \mathrm{M}$ MeJA treatment yielded the maximum triterpenoid production in diploid hairy roots of $27.25 \pm 0.27 \mu \mathrm{g} / \mathrm{mg}$ Dry weight (DW) total triterpenoid at day 21. For the tetraploid hairy root cultures, the 28th-day hairy root culture produced a maximum amount of triterpenoids of $16.29 \pm 6.32 \mu \mathrm{g} / \mathrm{mg} \mathrm{DW}$ in response to the $50 \mu \mathrm{M}$ MeJA treatment, whereas the $100 \mu \mathrm{M}$ MeJA treatment produced a similar triterpenoid amount $(16.31 \pm 9.24 \mu \mathrm{g} / \mathrm{mg} \mathrm{DW})$ at day 14 . Moreover, in response to $50 \mu \mathrm{M} \mathrm{MeJA}$, we obtained different ratios of aglycone to glycoside, i.e., 1:7 and 1:2, between the diploid and tetraploid hairy root cultures. Asiaticoside was the dominant phytochemical, followed by asiatic acid and madecassic acid. This study provides valuable information for producing triterpenoids for $C$. asiatica commercial products and preparations by using hairy root cultures.

Centella asiatica (L.) Urb. (Apiaceae) is a well-known medicinal plant in tropical and subtropical regions. The plant is a main ingredient of Ayurvedic preparations (India), traditional Chinese medicine (China), and commercial drugs in the European market ${ }^{1,2}$. Madecassoside, asiaticoside, madecassic acid and asiatic acid are the principle phytochemicals of C. asiatica and possess pharmacological activities such as wound healing ${ }^{3,4}$, memory improvement, cognition and mood modulation ${ }^{5}$. Although the demand for C. asiatica is increasing, conventional cultivation cannot guarantee phytomass and phytochemical production ${ }^{6,7}$. The triterpenoid amount of C. asiatica cultures varies among seasons, environmental conditions, cultivation regions and genotypes ${ }^{1,8}$.

In vitro hairy root culture, a disease caused by Agrobacterium rhizogenes infection, is an innovative platform for phytochemical production and a sustainable and economically feasible alternative to propagated plants ${ }^{9}$. The application of the elicitor, i.e., Methyl jasmonate (MeJA), is considered effective for enhancing terpenoid production in different plant cell, tissue and organ cultures, such as Panax ginseng cell culture ${ }^{10}$, $P$. ginseng hairy root culture $^{11}$, Glycyrrhiza glabra cell culture ${ }^{12}$, and C. asiatica whole plant culture ${ }^{13,14}$. In addition, several studies have reported high phytomass and phytochemical production by tetraploid medicinal plants relative to the levels in normal diploid plants, such as Papaver somniferum ${ }^{15}$, Artemisia annua ${ }^{16}$ and Salvia miltiorrhiza ${ }^{17}$. Higher phytomass and triterpenoid production from tetraploid greenhouse-grown and field-grown C. asiatica plants have been reported ${ }^{18,19}$. Therefore, the aims of the present study were (1) to establish an efficient hairy root induction protocol for diploid and tetraploid C. asiatica and (2) to study the effects of MeJA on the phytomass and triterpenoid production of diploid and tetraploid C. asiatica hairy roots.

${ }^{1}$ Department of Pharmaceutical Botany, Faculty of Pharmacy, Mahidol University, 447 Sri-ayuthaya Road, Bangkok, 10400, Thailand. 'Department of Plant Science, Faculty of Science, Mahidol University, 272 Rama VI Road, Ratchathewi, Bangkok, 10400, Thailand. *email: sompop.pra@mahidol.ac.th 


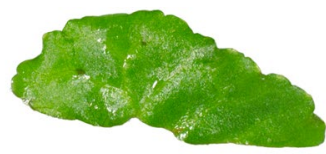

\section{Upper-part leaf}

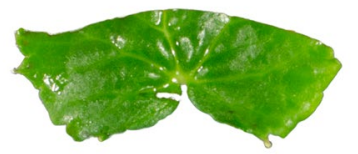

Lower-part leaf

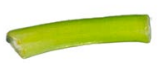

Petiole

Figure 1. Explant types of C. asiatica for A. rhizogenes infection. Bar $=1.0 \mathrm{~cm}$. (a) upper-part leaf explant, (b) lower-part leaf explant, (c) petiole explant.

\section{Materials and Methods}

Plant materials. Diploid and tetraploid C. asiatica plantlets were obtained from a previous study by Kaensaksiri et al. ${ }^{18}$. The plantlets were subcultured at 30-day intervals in semisolid Murashige and Skoog media $(\mathrm{MS} \text { media })^{20}$ supplemented with $3.0 \%$ sucrose and containing $5.5 \mathrm{~g} / 1$ Agargel ${ }^{\circledR}$, with a pH of 5.8. The plantlets were cultured at $25^{\circ} \mathrm{C}$ under a $16 \mathrm{~h}$ light $/ 8 \mathrm{~h}$ dark photoperiod. The 24 -day-old in vitro diploid and tetraploid $\mathrm{C}$. asiatica plantlets were separated into petioles and upper and lower parts of leaves (Fig. 1).

Hairy root culture induction. The hairy root induction of C. asiatica followed the protocol of Kim et al. ${ }^{21}$ with some modifications. One loop of each of the A. rhizogenes strains ATCC 43057 and ATCC 15834 (ATCC-USA) was cultured separately in $20 \mathrm{ml}$ Yeast mannitol broth (YMB) medium for 3 days under a $16 \mathrm{~h}$ light $/ 8 \mathrm{~h}$ dark photoperiod at $25^{\circ} \mathrm{C}$ and agitated at $110 \mathrm{rpm}$. Three-day-old bacterial suspension cultures were used for infection.

The explants were immersed in the bacterial suspension for $40 \mathrm{~min}$, placed in half-strength semisolid MS media supplemented with $50 \mu \mathrm{M}$ acetosyringone and cultured at $25^{\circ} \mathrm{C}$ in darkness. The coculture period spanned 3 days and was followed by decontamination of the bacteria with $500 \mathrm{mg} / \mathrm{l}$ cefotaxime for 14 days. The concentration of cefotaxime was reduced to $250 \mathrm{mg} / \mathrm{l}$ for the next 14 days and maintained in subculture in the same type of media until no bacteria were present.

The hairy roots were cultured in $50 \mathrm{ml}$ half-strength liquid MS media, subcultured at 30 -day intervals at $25^{\circ} \mathrm{C}$ in the dark and agitated at $110 \mathrm{rpm}$.

Hairy root confirmation and ploidy determination. Total DNA of the putative hairy roots was extracted by using a DNeasy plant mini kit (Qiagen, Germany) following the manufacturer's instructions. The primers for rolB amplification and the Polymerase chain reaction (PCR) conditions followed those in Furner et al. ${ }^{22}$ : The primers were rolB-1 primer $5^{\prime}$-GCTCTTGCAGTGCTAGATTT- $3^{\prime}$ and rolB-2 primer $5^{\prime}$-GAAGGTGCAAGCTACCTCTC-3'; and the PCR conditions were initial denaturation at $95^{\circ} \mathrm{C}$ for $2 \mathrm{~min}, 30$ cycles of denaturation at $95^{\circ} \mathrm{C}$ for $30 \mathrm{~min}$, annealing at $53.5^{\circ} \mathrm{C}$ for $45 \mathrm{~min}$ and extension at $72^{\circ} \mathrm{C}$ for $45 \mathrm{~min}$, and a final extension at $72^{\circ} \mathrm{C}$ for $6 \mathrm{~min}$. The PCR products were transferred to a $1.2 \%(\mathrm{w} / \mathrm{v})$ agarose gel for evaluation by gel electrophoresis. The data were recorded by a Gel Documentation instrument (Gene Genius, Syngene) under $\mathrm{UV}$ at $260 \mathrm{~nm}$ after staining with $\mathrm{SYBR}^{\circledR}$ Safe DNA gel stain (Fisher).

Ploidy-level determination followed the protocol of Dolezel et al. ${ }^{23}$. The data were recorded by a BD FACSCanto $^{\mathrm{TM}}$ flow cytometer (BD Biosciences). Diploid hairy roots were used as a control group.

Elicitor treatments. Kim et al. ${ }^{13}$ demonstrated that asiaticoside content increased when a whole plant culture was elicited by $10-100 \mu \mathrm{M} \mathrm{MeJA}$ and that the optimal concentration for elicitation was $100 \mu \mathrm{M} \mathrm{MeJA}$. However, they reported a negative effect of MeJA at high concentration on senescence of the whole plants. Mangas et al. ${ }^{24}$ reported that $50 \mu \mathrm{M}$ MeJA did not elicit a whole plant culture, in contrast to the results of Kim et al. ${ }^{13}$, and that asiaticoside content increased with increasing MeJA concentration (up to $100 \mu \mathrm{M}$ ). Moreover, $200 \mu \mathrm{M}$ MeJA treatment produced symptoms of root necrosis; thus, $100 \mu \mathrm{M}$ MeJA was considered the optimum treatment concentration ${ }^{24}$. In this study, we studied the effects of MeJA on hairy root culture; as hairy root culture is more sensitive than whole plant culture, we selected a safe range of MeJA concentrations and predicted that these concentrations would produce effects. The selected concentrations of MeJA were $0 \mu \mathrm{M}$ (as control), $50 \mu \mathrm{M}$ and $100 \mu \mathrm{M}$ (treatment).

A MeJA stock (Sigma-Aldrich) solution was diluted to different concentrations (i.e., $0.0 \mu \mathrm{M}, 50 \mu \mathrm{M}$ and $100 \mu \mathrm{M}$ ) by absolute ethanol (analytical grade). MeJA was applied to the hairy root cultures at the beginning of the 
experiment. Fresh weight (FW), Dry weight (DW) and triterpenoid production was recorded at 7-day intervals until day 28. The cultures of all treatments were cultured in the dark at $25^{\circ} \mathrm{C}$ and agitated at $110 \mathrm{rpm}$.

Growth determination and triterpenoid analysis. Three flasks of hairy roots were harvested from each MeJA treatment. FW was measured after the roots were media absorbed by sterilized tissue paper. The harvested hairy roots were dried at $40^{\circ} \mathrm{C}$ for $48 \mathrm{~h}$ in a hot-air oven to determine DW. The hairy roots were homogenized to powder and extracted twice with $80 \%$ methanol (extraction ratio: 5:1 w/v) by sonication for $15 \mathrm{~min}$. The extract was analyzed by a Thermo Scientific Ultra high-performance liquid chromatography (UHPLC) model Dionex Ultimate 3000 with a diode array detector using a protocol developed and validated by our research group (Thong-On, et al. ${ }^{19}$ ). A LiChroCART ${ }^{\circledR}$ column (LiChrospher ${ }^{\circledR} 100$ RP-18, $250 \mathrm{~mm} \times 4.0 \mathrm{~mm}$ I.D., particle size: $5.0 \mu \mathrm{m}$ ) and an acetonitrile and water (containing $0.1 \% \mathrm{H}_{3} \mathrm{PO}_{4}$ ) gradient system were used. The mobile phase system of acetonitrile was as follows: $20-35 \%$ (10 min), 35-65\% (15 min), 65-80\% (5 min), 80-20\% (5 min) and $20 \%(10 \mathrm{~min})$. The flow rate was $1.0 \mathrm{ml} / \mathrm{min}$, the injection volume was $20 \mu \mathrm{l}$, and $206 \mathrm{~nm}$ was used to detect the 4 major phytochemicals.

\section{Results and Discussion}

Confirmation of hairy root transformation and ploidy determination. The transgenic state of the hairy root lines was confirmed by the presence of $r o l B$ in the putative hairy root genome. There were 4 diploid hairy root lines (HRD1-4) (Fig. 2a) and 5 tetraploid hairy root lines (HRT1-5) (Fig. 2b). The healthy diploid and tetraploid hairy root lines were chosen to conduct the elicitation experiment.

In addition, rolB was detected in these hairy root lines, confirming the transformation (Supplement Information). The ploidy levels of the hairy root lines obtained from the tetraploid explants were determined by flow cytometry. The peaks of the tetraploid hairy roots $(4 \mathrm{x})$ and diploid control hairy roots $(2 \mathrm{x})$ were set at the channels 100 and 50, respectively (Fig. 3).

Effects of explant type and $\boldsymbol{A}$. rhizogenes strain on hairy root induction. At both ploidy levels, hairy roots were induced from the lower part of the leaf explants after 15-17 days, whereas 29 days elapsed before the petiole explants produced hairy roots. There was no hairy root induction from the upper parts of the leaves of explants of either ploidy level of C. asiatica. Hairy roots were induced directly from the cut ends of the explants. The hairy roots induced from tetraploid explants were confirmed to be tetraploid by flow cytometry. A higher transformation rate was observed from the lower parts of the leaves of diploid (5-10\%) and tetraploid explants (4.17-7.14\%) (Table 1). The A. rhizogenes strain ATCC 43057 was more virulent than the strain ATCC 15834 and thus infected more explant types, i.e., the petioles and lower parts of leaves, and induced a higher transformation rate. Variation in A. rhizogenes strain and explant type can lead to different results because of differences among bacteria in the ability to induce hairy roots and the different responses of explants to bacteria ${ }^{25,26}$. The high transformation rate of the lower parts of the leaves may have been observed because of the larger midveins at the base of the leaves than in the upper parts; these might have allowed a large number of bacterial host cells to be integrated into the genome of the plant. Moreover, the lower parts of the leaves had 2 cut ends, which increased the infection area relative to that at the upper parts. Therefore, the use of the lower parts of the leaves for infection by A. rhizogenes strain ATCC 43057 for three days in the darkness was efficient for achieving a high successful transformation rate for C. asiatica hairy root induction.

The characteristics of the hairy roots of differed between the diploid and tetraploid C. asiatica explants (Fig. 4). The diploid hairy roots displayed high lateral branch formation and rapid growth. Moreover, the dimensions of the primary hairy roots were similar to those of the lateral branches. However, the tetraploid hairy roots grew slowly and produced fewer lateral roots. The dimensions of the primary roots were larger than those of the lateral branches in tetraploid C. asiatica hairy roots.

Effects of MeJA on the growth of hairy root cultures. Figure 5 demonstrates the growth patterns of diploid and tetraploid hairy root cultures treated with different MeJA treatments. For the diploid hairy root cultures, the control treatment produced higher DW at day 28 than the other MeJA treatments, reaching $99.44 \pm 23.2 \mathrm{mg} /$ flask. The hairy root cultures of the $50 \mu \mathrm{M}$ MeJA treatment and the $100 \mu \mathrm{M} \mathrm{MeJA}$ treatment showed maximum DW of $28.02 \pm 8.05 \mathrm{mg} /$ flask and $18.50 \pm 2.78 \mathrm{mg} /$ flask, respectively, on day 21 . MeJA inhibited the growth of diploid hairy roots, especially those treated with high MeJA concentrations. The maximum DW for the tetraploid hairy root cultures was $22.14 \pm 11.48 \mathrm{mg} /$ flask at day 28 for the control treatment, $18.86 \pm 4.58 \mathrm{mg} /$ flask at day 28 for the $50 \mu \mathrm{M}$ MeJA treatment and $13.88 \pm 2.34 \mathrm{mg} /$ flask at day 21 for the $100 \mu \mathrm{M}$ MeJA treatment. The nonelicited tetraploid hairy roots grew but at a slower growth rate than the nonelicited diploid hairy roots. The growth of the nonelicited diploid hairy roots was 4.5 -fold higher than that of nonelicited tetraploid hairy roots at day 28. Inhibitory effects of MeJA have previously been reported on hairy root cultures of Rhinacanthus nasutus ${ }^{27}$ and Glycine max ${ }^{28}$. The reasons may be related to the phenolic compounds secreted from hairy roots, which are stimulated by the stress from MeJA, or the toxic effect of MeJA itself on the hairy roots ${ }^{29}$. Moreover, polyploidy plants may have a small number of cell divisions during growth and development that result in a lower growth rate than in normal diploid plants ${ }^{30,31}$. De Jesus-Gonzalez and Weathers ${ }^{32}$ reported similar results for Artemisia annua.

Effects of MeJA on the triterpenoid production of hairy root cultures. There was no triterpenoid production in nonelicited C. asiatica hairy root culture, whereas MeJA led to triterpenoid production in both diploid and tetraploid hairy root cultures (Tables 2 and 3). For the diploid hairy root cultures, the highest triterpenoid production under the 50 and $100 \mu \mathrm{M}$ MeJA treatments was $27.25 \pm 0.27 \mu \mathrm{g} / \mathrm{mg} \mathrm{DW}$ at day 21 and $6.17 \pm 2.30 \mu \mathrm{g} /$ 


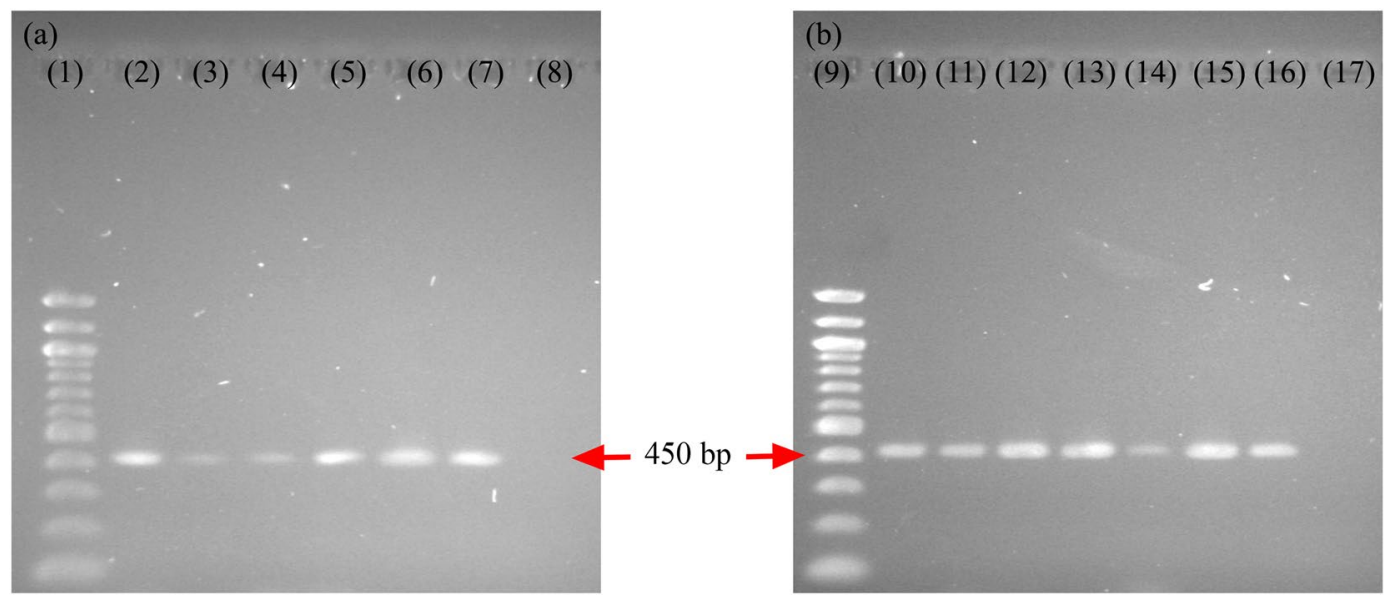

Figure 2. PCR analysis of the rolB gene of $A$. rhizogenes. (a) diploid hairy root lines; (b) tetraploid hairy root lines, lanes 1 and 9 DNA marker; lanes 8 and 17 distilled water (negative control); lanes 2-5 (HRD1, HRD2, HRD3, HRD4) and 10-14 (HRT1, HRT2, HRT3, HRT4, HRT5) amplified bands of rolB from the DNA of hairy root lines; lanes 6-7 and 15-16 amplified bands of rolB from A. rhizogenes (positive control).

(a)

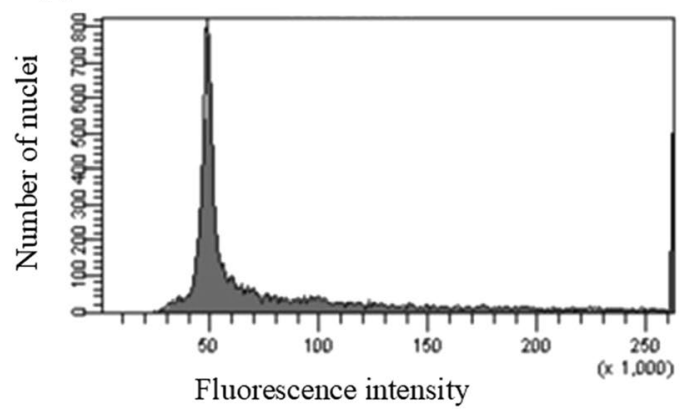

(b)

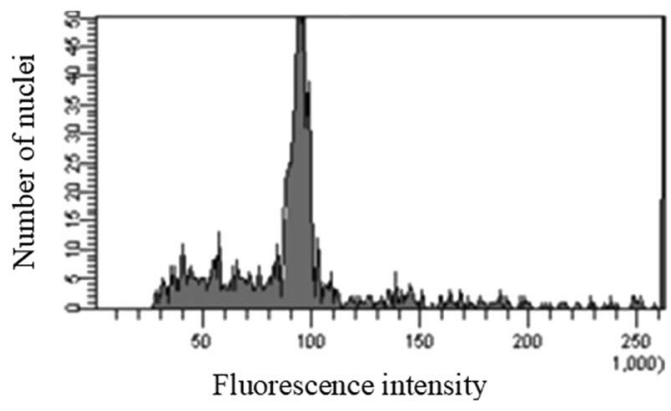

Figure 3. Flow cytometry histogram of C. asiatica hairy roots. (a) Histogram of a diploid control hairy root line, (b) histogram of a tetraploid hairy root line.

\begin{tabular}{|l|l|l|l|l|}
\hline \multirow{4}{*}{ Ploidy level } & \multirow{4}{*}{ A.rhizogenes strain } \\
\cline { 3 - 6 } & Explant types & Control & ATCC 43057 & ATCC 15834 \\
\hline \multirow{4}{*}{ Diploid plant } & Upper-leaf & - & - & - \\
\cline { 2 - 6 } & Lower-leaf & - & $10.00 \%$ & $5.00 \%$ \\
\cline { 2 - 6 } & Petiole & - & $2.38 \%$ & - \\
\hline \multirow{3}{*}{ Tetraploid plant } & Upper-leaf & - & - & - \\
\cline { 2 - 6 } & Lower-leaf & - & $7.14 \%$ & $4.17 \%$ \\
\cline { 2 - 6 } & Petiole & - & $5.26 \%$ & - \\
\hline
\end{tabular}

Table 1. Effect of explant type and A. rhizogenes strain on hairy root induction (\%) of C. asiatica.

mg DW at day 14 , respectively. When treated on the same day, the $50 \mu \mathrm{M}$ MeJA treatment produced more triterpenoids than the $100 \mu \mathrm{M}$ MeJA treatment. For the tetraploid hairy root cultures, in the $50 \mu \mathrm{M} \mathrm{MeJA}$ treatment, the hairy root culture at day 28 produced the maximum amount of triterpenoids, $16.29 \pm 6.32 \mu \mathrm{g} / \mathrm{mg}$ DW, whereas the $100 \mu \mathrm{M}$ MeJA treatment produced a similar triterpenoid amount $(16.31 \pm 9.24 \mu \mathrm{g} / \mathrm{mg} \mathrm{DW})$ at day 14 (Tables 2 and 3). Ploidy level $(p=0.0334)$, MeJA treatment $(p=0.0000)$ and number of days of culture $(p=0.0003)$ were the main factors that significantly affected the total triterpenoid production of $C$. asiatica hairy roots, as determined by 3-way analysis of variance. Furthermore, the triterpenoid production patterns in each ploidy level for all MeJA treatments differed in their production characteristics. Asiaticoside was dominant, followed by asiatic acid and madecassic acid. Madecassoside was not detected in hairy roots of either ploidy level. Interestingly, there were different ratios of aglycones (i.e., asiatic acid and madecassic acid) to glycoside (i.e., asiaticoside) when the hairy roots were treated with MeJA. The ratios in diploid and tetraploid hairy roots treated with $50 \mu \mathrm{M}$ MeJA at day 28 were 1:7 and 1:2, respectively. However, the ratios under $100 \mu \mathrm{M}$ MeJA treatment were similar between 


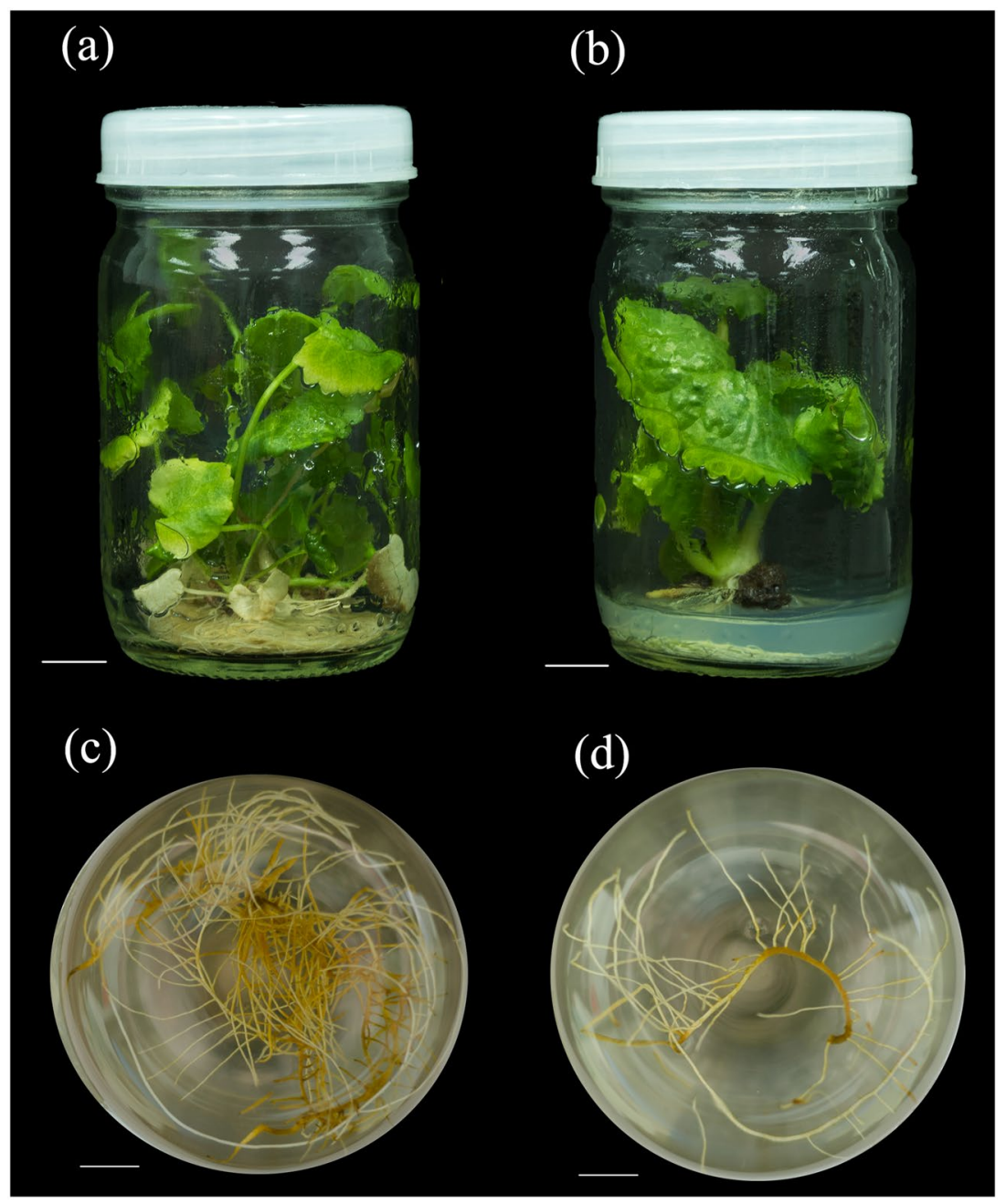

Figure 4. Diploid (a) and tetraploid (b) plants and derived diploid (c) and tetraploid (d) hairy root cultures of C. asiatica. $\mathrm{Bar}=1.0 \mathrm{~cm}$.

(a)

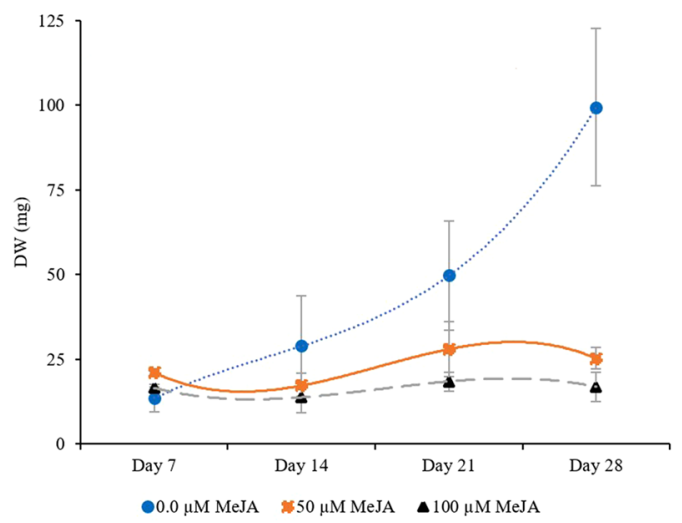

(b)

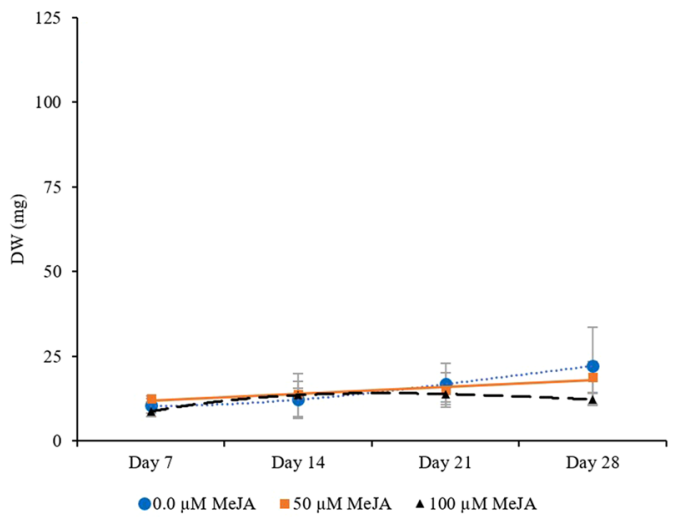

Figure 5. Growth patterns of diploid (a) and tetraploid (b) C. asiatica hairy root cultures. The data are presented as mean $\pm \mathrm{SD}$.

the diploid and tetraploid hairy roots, e.g., 1:1 on day 28. These results showed that the ratio of aglycones to glycoside in diploid hairy roots was affected by the concentration of MeJA, whereas the ratio was largely stable in the tetraploid hairy roots, even at high MeJA concentrations. Aziz et al. ${ }^{33}$ and Kim et al. ${ }^{34}$ reported that there was no triterpenoid production from nonelicited C. asiatica hairy root cultures. This result may be related to 


\begin{tabular}{|l|l|l|l|l|l|}
\hline MeJA & Harvest Date & AD & MA & AA & TT \\
\hline \multirow{5}{*}{$0 \mu \mathrm{M}$} & Day 7 & $0.00 \pm 0.00^{\mathrm{a}}$ & $0.00 \pm 0.00^{\mathrm{a}}$ & $0.00 \pm 0.00^{\mathrm{a}}$ & $0.00 \pm 0.00^{\mathrm{a}}$ \\
\cline { 2 - 6 } & Day 14 & $0.00 \pm 0.00^{\mathrm{a}}$ & $0.00 \pm 0.00^{\mathrm{a}}$ & $0.00 \pm 0.00^{\mathrm{a}}$ & $0.00 \pm 0.00^{\mathrm{a}}$ \\
\cline { 2 - 6 } & Day 21 & $0.00 \pm 0.00^{\mathrm{a}}$ & $0.00 \pm 0.00^{\mathrm{a}}$ & $0.00 \pm 0.00^{\mathrm{a}}$ & $0.00 \pm 0.00^{\mathrm{a}}$ \\
\cline { 2 - 6 } & Day 28 & $0.00 \pm 0.00^{\mathrm{a}}$ & $0.00 \pm 0.00^{\mathrm{a}}$ & $0.00 \pm 0.00^{\mathrm{a}}$ & $0.00 \pm 0.00^{\mathrm{a}}$ \\
\hline \multirow{5}{*}{$50 \mu \mathrm{M}$} & Day 7 & $15.35 \pm 9.71^{\mathrm{bc}}$ & $0.00 \pm 0.00^{\mathrm{a}}$ & $0.00 \pm 0.00^{\mathrm{a}}$ & $15.35 \pm 9.71^{\mathrm{c}}$ \\
\cline { 2 - 6 } & Day 14 & $11.67 \pm 3.49^{\mathrm{b}}$ & $0.00 \pm 0.00^{\mathrm{a}}$ & $0.00 \pm 0.00^{\mathrm{a}}$ & $11.67 \pm 3.49^{\mathrm{bc}}$ \\
\cline { 2 - 6 } & Day 21 & $25.87 \pm 0.93^{\mathrm{d}}$ & $0.47 \pm 0.16^{\mathrm{bc}}$ & $0.91 \pm 0.53^{\mathrm{abc}}$ & $27.25 \pm 0.27^{\mathrm{d}}$ \\
\cline { 2 - 6 } & Day 28 & $18.82 \pm 5.90^{\mathrm{c}}$ & $0.79 \pm 0.50^{\mathrm{c}}$ & $2.24 \pm 0.92^{\mathrm{d}}$ & $22.85 \pm 7.32^{\mathrm{d}}$ \\
\hline \multirow{3}{*}{$100 \mu \mathrm{M}$} & Day 7 & $4.20 \pm 0.76^{\mathrm{a}}$ & $0.00 \pm 0.00^{\mathrm{a}}$ & $0.00 \pm 0.00^{\mathrm{a}}$ & $4.20 \pm 0.76^{\mathrm{a}}$ \\
\cline { 2 - 6 } & Day 14 & $5.20 \pm 2.10^{\mathrm{a}}$ & $0.35 \pm 0.15^{\mathrm{ab}}$ & $0.62 \pm 0.33^{\mathrm{ab}}$ & $6.17 \pm 2.30^{\mathrm{ab}}$ \\
\cline { 2 - 6 } & Day 21 & $3.04 \pm 1.60^{\mathrm{a}}$ & $0.44 \pm 0.50^{\mathrm{bc}}$ & $1.28 \pm 1.43^{\mathrm{bc}}$ & $4.76 \pm 3.44^{\mathrm{ab}}$ \\
\cline { 2 - 6 } & Day 28 & $2.76 \pm 0.63^{\mathrm{a}}$ & $0.55 \pm 0.11^{\mathrm{bc}}$ & $1.66 \pm 0.30^{\mathrm{cd}}$ & $4.96 \pm 1.03^{\mathrm{ab}}$ \\
\hline
\end{tabular}

Table 2. Triterpenoid Production of diploid hairy root cultures (Mean \pm SD ( $\mu \mathrm{g} / \mathrm{mg} \mathrm{DW})$ ). Means within each column with different letters are significantly different at $\mathrm{P}<0.05$. TT: Total triterpenoid, $\mathrm{AD}$ : Asiaticoside, MA: Madecassic Acid, AA: Asiatic Acid.

\begin{tabular}{|l|l|l|l|l|l|}
\hline MeJA & Harvest Date & AD & MA & AA & TT \\
\hline \multirow{5}{*}{$0 \mu \mathrm{M}$} & Day 7 & $0.00 \pm 0.00^{\mathrm{a}}$ & $0.00 \pm 0.00^{\mathrm{a}}$ & $0.00 \pm 0.00^{\mathrm{a}}$ & $0.00 \pm 0.00^{\mathrm{a}}$ \\
\cline { 2 - 6 } & Day 14 & $0.00 \pm 0.00^{\mathrm{a}}$ & $0.00 \pm 0.00^{\mathrm{a}}$ & $0.00 \pm 0.00^{\mathrm{a}}$ & $0.00 \pm 0.00^{\mathrm{a}}$ \\
\cline { 2 - 6 } & Day 21 & $0.00 \pm 0.00^{\mathrm{a}}$ & $0.00 \pm 0.00^{\mathrm{a}}$ & $0.00 \pm 0.00^{\mathrm{a}}$ & $0.00 \pm 0.00^{\mathrm{a}}$ \\
\cline { 2 - 6 } & Day 28 & $0.00 \pm 0.00^{\mathrm{a}}$ & $0.00 \pm 0.00^{\mathrm{a}}$ & $0.00 \pm 0.00^{\mathrm{a}}$ & $0.00 \pm 0.00^{\mathrm{a}}$ \\
\hline \multirow{5}{*}{$50 \mu \mathrm{M}$} & Day 7 & $0.00 \pm 0.00^{\mathrm{a}}$ & $0.00 \pm 0.00^{\mathrm{a}}$ & $0.00 \pm 0.00^{\mathrm{a}}$ & $0.00 \pm 0.00^{\mathrm{a}}$ \\
\cline { 2 - 6 } & Day 14 & $0.00 \pm 0.00^{\mathrm{a}}$ & $0.37 \pm 0.20^{\mathrm{ab}}$ & $0.00 \pm 0.00^{\mathrm{a}}$ & $0.37 \pm 0.20^{\mathrm{a}}$ \\
\cline { 2 - 6 } & Day 21 & $5.83 \pm 3.37^{\mathrm{abc}}$ & $0.65 \pm 0.23^{\mathrm{ab}}$ & $1.84 \pm 0.29^{\mathrm{ab}}$ & $8.32 \pm 2.87^{\mathrm{abc}}$ \\
\cline { 2 - 6 } & Day 28 & $10.72 \pm 4.25^{\mathrm{cd}}$ & $1.40 \pm 0.69^{\mathrm{cd}}$ & $4.17 \pm 1.38^{\mathrm{c}}$ & $16.29 \pm 6.32^{\mathrm{c}}$ \\
\hline \multirow{3}{*}{$100 \mu \mathrm{M}$} & Day 7 & $3.49 \pm 3.03^{\mathrm{ab}}$ & $0.00 \pm 0.00^{\mathrm{a}}$ & $0.00 \pm 0.00^{\mathrm{a}}$ & $3.49 \pm 3.03^{\mathrm{ab}}$ \\
\cline { 2 - 6 } & Day 14 & $14.39 \pm 7.86^{\mathrm{d}}$ & $0.51 \pm 0.21^{\mathrm{ab}}$ & $1.41 \pm 1.22^{\mathrm{ab}}$ & $16.31 \pm 9.24^{\mathrm{c}}$ \\
\cline { 2 - 6 } & Day 21 & $7.60 \pm 7.19^{\mathrm{bc}}$ & $0.82 \pm 0.58^{\mathrm{bc}}$ & $2.20 \pm 1.9^{\mathrm{b}}$ & $10.62 \pm 9.34^{\mathrm{bc}}$ \\
\cline { 2 - 6 } & Day 28 & $7.95 \pm 2.06^{\mathrm{bc}}$ & $1.85 \pm 1.04^{\mathrm{d}}$ & $5.69 \pm 1.96^{\mathrm{c}}$ & $15.49 \pm 4.93^{\mathrm{c}}$ \\
\hline
\end{tabular}

Table 3. Triterpenoid Production of tetraploid hairy root cultures (Mean $\pm S D(\mu g / m g ~ D W))$. Means within each column with different letters are significantly different at $\mathrm{P}<0.05$. TT: Total triterpenoid, AD: Asiaticoside, MA: Madecassic Acid, AA: Asiatic Acid.

organ-specific biosynthesis, which involves interactions between plant organs and plant metabolic precursors produced in roots and transported to aerial parts for bioconversion ${ }^{33}$. Moreover, the genes associated with triterpenoid biosynthesis may be poorly expressed in transgenic roots ${ }^{34}$. In contrast, the addition of MeJA to the hairy root cultures resulted in triterpenoid production, possibly because of the upregulation of CaSQS (Centella asiatica squalene synthase) and CabAS (Centella asiatica $\beta$-amyrin synthase) genes ${ }^{21,35}$. Previous studies reported different proportions of triterpenoids in 4-month-old field-grown diploid and tetraploid C. asiatica plants ${ }^{18,19}$. The ratios of aglycones to glycosides were 1:13 and 1:9 in diploid and tetraploid leaves, respectively. In the present study, the tetraploid hairy roots produced more glycones than did the diploid hairy roots, which increased the aglycone/glycoside ratio to $1: 2$ and 1:1 under treatment with 50 and $100 \mu \mathrm{M}$ MeJA, respectively, at day 28 . The downregulation of UDP-glucosyltransferases in the tetraploid hairy roots by MeJA may have contributed to the different proportions between the plants of different ploidies ${ }^{36}$. Commercial drugs produced from C. asiatica and other preparations consist of $60 \%$ aglycones and $40 \%$ asiaticoside (equivalent to a 3:2 ratio) ${ }^{1,2}$. The manufacturing processes of these $C$. asiatica drugs and preparations are complex and involve chemical treatments that cannot maintain the proportions of natural components. Purified chemicals are also added to enrich the extract, which may affect the price of $C$. asiatica products ${ }^{2}$. By using elicited tetraploid hairy roots, these production obstacles may be solved. The findings indicate that $C$. asiatica hairy roots cannot produce the four major triterpenoids without intervention, which may be related to organ-specific biosynthesis. The application of MeJA resulted in not only triterpenoid production but also differences in triterpenoid proportion between diploid and tetraploid hairy root cultures. The diploid hairy roots were suitable for glycoside production, and the tetraploid hairy roots were suitable for aglycone production. Moreover, $50 \mu \mathrm{M}$ MeJA was the optimum concentration for maximizing the amount of triterpenoids per flask from C. asiatica hairy roots of both ploidy levels.

Received: 10 July 2019; Accepted: 14 November 2019;

Published online: 10 December 2019 


\section{References}

1. Brinkhaus, B., Lindner, M., Schuppan, D. \& Hahn, E. G. Chemical, pharmacological and clinical profile of the East Asian medical plant Centella asiatica. Phytomedicine 7, 427-448, https://doi.org/10.1016/S0944-7113(00)80065-3 (2000).

2. Delbò, M. \& Calapai, G. Assessment report on Centella asiatica (L.) Urban, herba. (European Medicines Agency, United Kingdom, 2010).

3. Liu, M. et al. Madecassoside isolated from Centella asiatica herbs facilitates burn wound healing in mice. Planta Med. 74, 809-815, https://doi.org/10.1055/s-2008-1074533 (2008).

4. Shukla, A. et al. In vitro and in vivo wound healing activity of asiaticoside isolated from Centella asiatica. J. Ethnopharmacol. 65 , 1-11, https://doi.org/10.1016/S0378-8741(98)00141-X (1999).

5. Wattanathorn, J. et al. Positive modulation of cognition and mood in the healthy elderly volunteer following the administration of Centella asiatica. J. Ethnopharmacol. 116, 325-332, https://doi.org/10.1016/j.jep.2007.11.038 (2008).

6. Tiwari, K. M., Sharma, N. C., Tiwari, V. \& Singh, B. D. Micropropagation of Centella asiatica (L.), a valuable medicinal herb. Plant Cell Tiss. Org. Cult. 63, 179-185, https://doi.org/10.1023/A:101069060 (2000)

7. Thomas, M. T. et al. Elite genotypes/chemotypes, with high contents of madecassoside and asiaticoside, from sixty accessions of Centella asiatica of south India and the Andaman Islands: For cultivation and utility in cosmetic and herbal drug applications. Ind. Crop. Prod. 32, 545-550, https://doi.org/10.1016/jandcrop.2010.07.003 (2010).

8. Randriamampionona, D. et al. Comparative analysis of active constituents in Centella asiatica samples from Madagascar: application for ex situ conservation and clonal propagation. Fitoterapia 78, 482-489, https://doi.org/10.1016/j.fitote.2007.03.016 (2007).

9. Eibl, R. \& Eibl, D. In Plant Biotechnology and Transgenic Plants (eds Kirsi-Marja Oksmah-Caldentey \& Wolfgang H. Barz) Ch. 8, 163-199 (Marcel Dekker, 2002).

10. Lu, M. B., Wong, H. L. \& Teng, W. L. Effects of elicitation on the production of saponin in cell culture of Panax ginseng. Plant Cell Rep. 20, 674-677, https://doi.org/10.1007/s002990100378 (2001).

11. Kim, O. T. et al. Upregulation of ginsenoside and gene expression related to triterpene biosynthesis in ginseng hairy root cultures elicited by methyl jasmonate. Plant Cell Tiss. Org. Cult. 98, 25-33, https://doi.org/10.1007/s11240-009-9535-9 (2009).

12. Hayashi, H., Huang, P. \& Inoue, K. Up-regulation of soyasaponin biosynthesis by methyl jasmonate in cultured cells of Glycyrrhiza glabra. Plant Cell Physiol 44, 404-411 (2003).

13. Kim, O. T., Kim, M. Y., Hong, M. H., Ahn, J. C. \& Hwang, B. Stimulation of asiaticoside accumulation in the whole plant cultures of Centella asiatica (L.) Urban by elicitors. Plant Cell Rep. 23, 339-344, https://doi.org/10.1007/s00299-004-0826-7 (2004).

14. Yoo, N. H. et al. Enhancement of centelloside production from cultured plants of Centella asiatica by combination of thidiazuron and methyl jasmonate. Plant Biotechnol. Rep. 5, 283-287, https://doi.org/10.1007/s11816-011-0173-4 (2011).

15. Mishra, B. K., Pathak, S., Sharma, A., Trivedi, P. K. \& Shukla, S. Modulated gene expression in newly synthesized auto-tetraploid of Papaver somniferum L. S. Afr. J. Bot. 76, 447-452, https://doi.org/10.1016/j.sajb.2010.02.090 (2010).

16. Wallaart, T. E., Pras, N. \& Quax, W. J. Seasonal variations of artemisinin and its biosynthetic precursors in tetraploid Artemisia annua plants compared with the diploid wild-type. Planta Med. 65, 723-728, https://doi.org/10.1055/s-1999-14094 (1999).

17. Gao, S. L., Zhu, D. N., Cai, Z. H. \& Xu, D. R. Autotetraploid plants from colchicine-treated bud culture of Salvia miltiorrhiza Bge. Plant Cell Tiss. Org. Cult. 47, 73-77, https://doi.org/10.1007/bf02318968 (1996).

18. Kaensaksiri, T., Soontornchainaksaeng, P., Soonthornchareonnon, N. \& Prathanturarug, S. In vitro induction of polyploidy in Centella asiatica (L.) Urban. Plant Cell Tiss. Org. Cult. 107, 187-194, https://doi.org/10.1007/s11240-011-9969-8 (2011).

19. Thong-On, W., Arimatsu, P., Pitiporn, S., Soonthornchareonnon, N. \& Prathanturarug, S. Field evaluation of in vitro-induced tetraploid and diploid Centella asiatica (L.) Urban. J. Nat. Med. 68, 267-273, https://doi.org/10.1007/s11418-013-0761-4 (2014).

20. Murashige, T. \& Skoog, F. A revised medium for rapid growth and bio assays with tobacco tissue cultures. Physiol. Plant. 15, 473-497, https://doi.org/10.1111/j.1399-3054.1962.tb08052.x (1962).

21. Kim, O. T. et al. Enhanced production of asiaticoside from hairy root cultures of Centella asiatica (L.) Urban elicited by methyl jasmonate. Plant Cell Rep. 26, 1941-1949, https://doi.org/10.1007/s00299-007-0400-1 (2007).

22. Furner, I. J. et al. An Agrobacterium transformation in the evolution of the genus Nicotiana. Nature 319, 422-427, https://doi. org/10.1038/319422a0 (1986)

23. Dolezel, J., Greilhuber, J. \& Suda, J. Estimation of nuclear DNA content in plants using flow cytometry. Nat. Protoc. 2, 2233-2244, https://doi.org/10.1038/nprot.2007.310 (2007).

24. Mangas, S. et al. The effect of methyl jasmonate on triterpene and sterol metabolisms of Centella asiatica, Ruscus aculeatus and Galphimia glauca cultured plants. Phytochemistry 67, 2041-2049, https://doi.org/10.1016/j.phytochem.2006.06.025 (2006).

25. Danphitsanuparn, P., Boonsnongcheep, P., Boriboonkaset, T., Chintapakorn, Y. \& Prathanturarug, S. Effects of Agrobacterium rhizogenes strains and other parameters on production of isoflavonoids in hairy roots of Pueraria candollei Grah. ex Benth. var. candollei. Plant Cell Tiss. Org. Cult. 111, 315-322, https://doi.org/10.1007/s11240-012-0196-8 (2012).

26. Ha, L. T. et al. Hairy root cultures of Panax vietnamensis, a promising approach for the production of ocotillol-type ginsenosides. Plant Cell Tiss. Org. Cult. 126, 93-103, https://doi.org/10.1007/s11240-016-0980-y (2016).

27. Cheruvathur, M. K. \& Thomas, T. D. Effect of plant growth regulators and elicitors on rhinacanthin accumulation in hairy root cultures of Rhinacanthus nasutus (L.) Kurz. Plant Cell Tiss. Org. Cult. 118, 169-177, https://doi.org/10.1007/s11240-014-0473-9 (2014).

28. Theboral, J. et al. Enhanced production of isoflavones by elicitation in hairy root cultures of Soybean. Plant Cell Tiss. Org. Cult. 117, 477-481, https://doi.org/10.1007/s11240-014-0450-3 (2014).

29. Sivanandhan, G. et al. Optimization of elicitation conditions with methyl jasmonate and salicylic acid to improve the productivity of withanolides in the adventitious root culture of Withania somnifera (1.) Dunal. Appl. Biochem. Biotechnol. 168, 681-696, https:// doi.org/10.1007/s12010-012-9809-2 (2012).

30. Lewis, W. H. In Polyploidy: Biological Relevance (ed. Walter H. Lewis) 103-144 (Springer US, 1980).

31. Otto, S. P. \& Whitton, J. Polyploid incidence and evolution. Annu. Rev. Genet. 34, 401-437, https://doi.org/10.1146/annurev. genet.34.1.401 (2000).

32. De Jesus-Gonzalez, L. \& Weathers, P. J. Tetraploid Artemisia annua hairy roots produce more artemisinin than diploids. Plant Cell Rep. 21, 809-813, https://doi.org/10.1007/s00299-003-0587-8 (2003).

33. Aziz, Z. A. et al. Production of asiaticoside and madecassoside in Centella asiatica in vitro and in vivo. Biol. Plant. 51, 34-42, https:// doi.org/10.1007/s10535-007-0008-x (2007).

34. Kim, O. T. et al. Upregulation of phytosterol and triterpene biosynthesis in Centella asiatica hairy roots overexpressed ginseng farnesyl diphosphate synthase. Plant Cell Rep. 29, 403-411, https://doi.org/10.1007/s00299-010-0831-y (2010).

35. Kim, O. T., Seong, N. S., Kim, M. Y. \& Hwang, B. Isolation and characterization of squalene synthase cDNA from Centella asiatica (L.) Urban. Journal of Plant Biology 48, 263-269, https://doi.org/10.1007/Bf03030521 (2005).

36. Kim, O. T. et al. Analysis of expressed sequence tags from Centella asiatica (L.) Urban hairy roots elicited by methyl jasmonate to discover genes related to cytochrome P450s and glucosyltransferases. Plant Biotechnol. Rep. 8, 211-220, https://doi.org/10.1007/ s11816-013-0311-2 (2014). 


\section{Author contributions}

K.V.N. conducted all experiments, collected and analyzed data, and drafted the manuscript. B.P., T.P. and U.V. participated in data analysis, discussion and recommendation. S.P. participated in research conception and design, data analysis, and manuscript revision.

\section{Competing interests}

The authors declare no competing interests.

\section{Additional information}

Supplementary information is available for this paper at https://doi.org/10.1038/s41598-019-54460-z.

Correspondence and requests for materials should be addressed to S.P.

Reprints and permissions information is available at www.nature.com/reprints.

Publisher's note Springer Nature remains neutral with regard to jurisdictional claims in published maps and institutional affiliations.

(c) (i) Open Access This article is licensed under a Creative Commons Attribution 4.0 International License, which permits use, sharing, adaptation, distribution and reproduction in any medium or format, as long as you give appropriate credit to the original author(s) and the source, provide a link to the Creative Commons license, and indicate if changes were made. The images or other third party material in this article are included in the article's Creative Commons license, unless indicated otherwise in a credit line to the material. If material is not included in the article's Creative Commons license and your intended use is not permitted by statutory regulation or exceeds the permitted use, you will need to obtain permission directly from the copyright holder. To view a copy of this license, visit http://creativecommons.org/licenses/by/4.0/.

(c) The Author(s) 2019 